\title{
Practical Exploration of Differentiated Teaching in the Process of Practical Teaching A Case Study of Mechanical Design Course Design
}

\author{
Huang Bin, Wang Kai \\ Foshan University, Foshan Guangdong, 528231, China
}

\begin{abstract}
Students' individual differences, teaching resources and school hours are facing new challenges for practical teaching. In this case, how to ensure the teaching quality within the limited school hours has become a new difficult problem for colleges and universities to train talents, and the differentiated teaching with strong pertinence and in line with the development of students has brought a new way out for practical teaching. In this paper, the application of differentiated teaching in practice teaching process is explored based on the practice teaching of Mechanical Design Curriculum Design of Class 17 vehicle engineering students.
\end{abstract}

Keywords: mechanical design course design; differentiated teaching; layered teaching

With the rapid development of society and the integration of industries, China's industrial scale has been in the leading position in the world. The social demand for engineering talents has crossed from full-time theoretical talents and full-time practical talents to compound talents with equal emphasis on theory and practice. This practical requirement puts forward new requirements and challenges to the practical teaching methods of mechanical specialty in colleges and universities. As a practical teaching backbone course of mechanical specialty ," Mechanical Design Course Design "needs to be reformed and explored to meet the needs of the future mechanical industry.

https://doi.org/10.47852/bonviewCETR2020010226

This is an open access article published by the BON VIEW PUBLISHING PTE. under the Creative Commons Attributions License. 


\section{Problems of Practical Teaching}

Practical teaching is an effective way to consolidate theoretical knowledge and deepen theoretical understanding. It is an important link to cultivate high-quality engineering and technical personnel with innovative consciousness, but there are many problems ${ }^{[1][2]}$ in the process of practical teaching. As far as the process of practical guidance is concerned, teachers are faced with the reduction of practical learning time, the selection of optional topics, the allocation of teaching resources is close to the critical point, and the practical content is difficult to combine with reality, which leads to the unsatisfactory quality of teaching. On the other hand, from the process of practical operation, each student's own teaching environment leads to the students' own understanding of knowledge construction differences, unified teaching methods, weakened the pertinence of practical teaching, Can not achieve the ideal teaching effect ${ }^{[3]}$. At the same time, students' own mastery of knowledge, knowledge acceptance ability, learning focus, curriculum suitability and professional identity directly affect the quality of students' learning. The above problems have existed for a long time in the process of practical teaching, which greatly affects the quality of teaching. Therefore, effective teaching methods should be adopted to improve the quality of teaching.

\section{The Necessity of Differentiated Teaching in Practice Teaching}

Traditional education is difficult to take into account the individual differences of students, can not stimulate students' subjective initiative, restrict the improvement of students' ability, and is not conducive to promoting the development of students. In order to make students develop, teachers should first face up to the individual differences of students, minimize the practice of rigid teaching, and make the students' knowledge and ability get the greatest development on the basis of the original. Therefore, differentiated teaching is an inevitable choice to improve students' quality.

Differentiated teaching is a teacher in the teaching process according to the objective differences of students, purposeful, planned, organized to guide students to actively and consciously learn, quickly improve students' learning efficiency, to achieve ${ }^{[4]}$ teaching objectives. The essence of differentiated teaching is to adjust the ${ }^{[5]}$ on the basis of traditional teaching, so that students of different degrees can master the knowledge points required by the syllabus in practical teaching. The main purpose of differentiated teaching is to adjust the practical problems and practice environment for students of different degrees, so that students of different degrees can complete the learning objectives of the syllabus within the prescribed time, and let students with learning difficulties meet the minimum requirements of teaching. Let the excellent students get greater development.

The advantages of differentiated teaching in practical teaching are as follows :(1) it is helpful to 
form a good learning attitude and avoid the negative psychology of some students due to the difference of ability in practice. All students experience a sense of success. Enhanced learning confidence. (2) It is beneficial to improve the quality and efficiency of teaching, so that teachers can implement appropriate teaching methods according to different levels of students, and increase the communication between teachers and students. (3) It is beneficial to improve teachers' ability and exercise teachers' professional level by arranging students' questions and teaching methods effectively and reasonably.

\section{Application Exploration of Differentiated Teaching in Practice Teaching}

According to the practice of differentiated teaching in practical teaching, teachers need to establish a differentiated teaching view, analyze and study the students' learning situation, combine with the specific situation and make the differentiated teaching task ${ }^{[6]}$. In the process of guidance, different communication methods are used to arouse students' enthusiasm and guide students to participate in thinking and discussion in order to achieve teaching objectives. The application of differentiated teaching in practice teaching will be explored with the design of mechanical design course of class 17 vehicle engineering class.

In the practical exploration of Mechanical Design Curriculum Design, the specific operation includes topic design, student stratification and process guidance. The first is topic design, which is the key to differentiated teaching. Design of the Course of Mechanical Design is usually the design of the mechanical device. According to the design of the general scheme of the transmission device, the assembly drawing of the reducer and the part drawing such as the gear and shaft are designed and calculated. In this experiment, from difficult to easy are single stage worm drive, bevel cylindrical gear drive, double stage cylindrical gear drive, single stage bevel gear drive and single stage cylindrical gear drive, and make independent design parameters for each student. The most difficult problem needs students to find the design data from outside the textbook to complete, and the lowest difficulty single stage cylindrical gear transmission only needs students to imitate the textbook to complete. In addition to meeting the teaching requirements of most secondary students, this kind of topic setting can also meet the practical needs of those who have difficulties in learning, realize the full coverage of teaching objects, and ensure that students can complete the practical links on time. It ensures the quality of students' study.

Then, the students in the class are stratified. Stratification is mainly based on the students' achievements in the theory course, supplemented by the voluntary nature of students to avoid compulsion. At the same time, through communication with students, class teachers, counselors, and academic staff, to understand the specific learning situation of students. The results of the students participating in the experiment are normally distributed, and the students are divided into five levels 
according to the difficulty of the subject. The first level is the excellent students, which has a correct attitude, solid foundation and courage to explore. In the process of stratification, we should try to blur and avoid making students feel different and affect their learning process.

Finally, the process guidance of practical links, because the students in the class have been divided into different levels, therefore, students at different levels need to take different ways of guidance, especially the first and fifth levels of students, Need to guide in a special way. For the first level of students, in the process of guidance is to take the way of guidance. By asking questions, we can guide students to broaden their knowledge on the basis of guiding teaching materials, stimulate their initiative to find design reference resources independently, and strengthen their ability of autonomous learning and knowledge application. At the same time, students at this level are encouraged to undertake to guide other levels of students, especially the fifth level students, in the course of guidance to strengthen their theoretical knowledge and practical skills. For the fifth level of students, it is necessary to use slightly compulsory means to check their daily completion progress, set the completion node time for them, and provide special guidance for the weak links. Encourage them to communicate more with first-level students. The middle-level students according to the requirements of the syllabus and the progress of practical links, unified guidance. In order to meet the requirements of the overall practical teaching, and then subdivide according to different levels, the second level students adopt the way of partial guidance, urge them to close to the first level students, and strengthen the supervision of the fourth level students. In this way, it can not only blur the sensitivity of students to differentiated teaching, but also implement appropriate teaching measures for students with different abilities.

Finally, the process guidance of practical links, because the students in the class have been divided into different levels, therefore, students at different levels need to take different ways of guidance, especially the first and fifth levels of students, Need to guide in a special way. For the first level of students, in the process of guidance is to take the way of guidance. By asking questions, we can guide students to broaden their knowledge on the basis of guiding teaching materials, stimulate their initiative to find design reference resources independently, and strengthen their ability of autonomous learning and knowledge application. At the same time, students at this level are encouraged to undertake to guide other levels of students, especially the fifth level students, in the course of guidance to strengthen their theoretical knowledge and practical skills. For the fifth level of students, it is necessary to use slightly compulsory means to check their daily completion progress, set the completion node time for them, and provide special guidance for the weak links. Encourage them to communicate more with first-level students. The middle-level students according to the requirements of the syllabus and the progress of practical links, unified guidance. In order to meet the requirements of the overall practical teaching, and then subdivide according to different levels, the second level students adopt the way of partial guidance, 
urge them to close to the first level students, and strengthen the supervision of the fourth level students. In this way, it can not only blur the sensitivity of students to differentiated teaching, but also implement appropriate teaching measures for students with different abilities.

Table 1. Difficulty and completion time distribution

\begin{tabular}{|c|c|c|c|}
\hline complexity & subject & number of people & Completion days \\
\hline easy & Single cylinder & 6 & 13.17 \\
\hline & Single cone & 8 & 14.25 \\
\hline & Double cylinder & 11 & 14.00 \\
\hline & Double conical cylinder & 9 & 13.56 \\
\hline difficult & Single worm & 6 & 13.33 \\
\hline
\end{tabular}

Table 2. Distribution of accomplishments and completion times

\begin{tabular}{|c|c|c|}
\hline Course Design Performance Distribution & number of people & Completion days \\
\hline $90-99$ & 6 & 12.80 \\
\hline $80-89$ & 24 & 13.79 \\
\hline $70-79$ & 11 & 14.00 \\
\hline
\end{tabular}

\section{Problems of Alienation Teaching in Practice Teaching}

Differentiated teaching has its advantages in practical teaching, but there are also some problems :(1) the main basis of students' stratification is to refer to the results of theoretical courses, and in the final analysis, teachers are the dominant ones. Whether the determination of the degree of difficulty, process guidance, performance evaluation, etc., is scientific and objective, and the choice and reference of evaluation dimension are all worthy of consideration. (2) The stratification of differentiated teaching is dynamic, and the standard of differentiated teaching for different courses may be completely different, in which case the adaptation of students should be considered. (3) Differentiated teaching is different from individualized teaching and fast and slow class teaching. The former mainly emphasizes students' personality differences, but it is difficult to estimate the overall development of the class. (4) The operation of differentiated teaching in practice is difficult for teachers to master, and teachers' understanding of differentiated teaching is different, so it is difficult to form a systematic teaching method. (5) The implementation of differentiated teaching will increase the workload of teachers. Although the working time is short, the intensity of work will increase greatly, and it is difficult to average the quality of differentiated teaching. 


\section{Experience and recommendations}

The application of differentiated teaching in practice can maximize the appropriate education for each student, enhance the pertinence of the guiding process, improve the efficiency of teaching, and adapt to the trend of compressed school hours in colleges and universities. However, there are also shortcomings in differentiated teaching. How to make good use of differentiated teaching in practice will be a new subject, and new theories and methods will constantly. At the same time, differentiated teaching is one of many teaching means, which will not replace the existing teaching methods, but will integrate differentiated teaching into the innovative exploration of modern teaching, broaden the teaching ideas and bring a new scene to college education.

\section{Acknowledgement}

This work is supported in part by Guangdong Science Foundation, Hybrid Adaptive Slicing Strategy and Fusion Mechanism Based on Geometric Features, No.2018A030310352; Foshan Key Technology Project, Development and industrial application of aluminum alloy materials for new energy vehicles, No.1920001000409; Key Laboratory of Modern Ceramic and Aluminium Profile Equipment of Guangdong Regular Higher Education, No.2017KSYS012.

\section{References}

[1] Huang Xiaolong, Liu Xiangquan. [J].] Research and Practice of Course Design Reform of Mechanical Principles China Science and Technology Information ,2011(24):182-182.

[2] Guan Shan, Wang Mingqiu. Study on the Complementary Advantages of Traditional Teaching Method and Multimedia Teaching Method —_ Application of J]. in Mechanical Drawing Teaching Journal of Northeast Electric Power University ,2012,32(1):93-96.

[3] Peng Qing. A Reflections on the Hierarchical Teaching Reform under the J]. of Class Teaching System in Colleges and Universities Journal of Wuxi Institute of Education 2006(03):63-65.

[4] Huang Ying. A Study on Differentiation Teaching in China [J].] in China Education and culture 2010(10):134-136...

[5] Chen Cailing. Study on the Application of POEC Differentiation Teaching in Inorganic Chemistry [J].] Course Journal of Heilongjiang Institute of political and legal Management ,2015(2).

[6] Yan Zhiqin. Application of Differentiated Teaching in Teaching Practice in Colleges and Universities [J]. Occupation ,2015(5):109-111. 